\title{
Effect of various adjuvants on growth and development of the entomopathogenic fungi Nomuraea rileyi (Farlow) Samson
}

\author{
S.D. PATIL* AND R.S. JADHAV ${ }^{1}$ \\ Agricultural Research Station, NIPHAD (M.S.) INDIA \\ ${ }^{1}$ Department of Entomology, College of Agriculture, Malegaon, NASIK (M.S.) INDIA
}

\section{ARITCLE INFO}

Received : 03.08 .2016

Revised : 13.09 .2016

Accepted : 27.09.2016

\section{KEY WORDS :}

Nomuraea rileyi, Adjuvants, Glycerol, Sunflower oil, Tween 80, Honey, Carboxymethyl cellulose

*Corresponding author: Email : saurushrutu@gmail.com

\begin{abstract}
Studies on the effect of various adjuvants on growth and development of Nomuraea rileyi (Farlow) Samson was undertaken with a view to select suitable adjuvant for developing formulation. It was revealed that the $N$.rileyi formulations with combination of adjuvants helped in increasing production of fungal biomass at 10 DAI. Based on the results it is concluded that the overall performance of the adjuvants for growth and development of $N$.rileyi in series of lab experimentation out of 96 test formulations. 10 formulation comprising 1) $N . r+\mathrm{HO}(1 \%), 2) N . r+\mathrm{SFO}(1 \%), 3) N . r .+\mathrm{GH}(0.5 \%), 4)$ $N . r+\mathrm{TW}(0.5 \%)+\mathrm{GH}(0.5 \%), 5) N . r .+\mathrm{GLY}(2 \%)+\mathrm{SFO}(1 \%), 6) N . r+\mathrm{GLY}(2 \%)+\mathrm{GH}(0.5 \%), 7)$ $N . r+\mathrm{SFO}(1 \%)+\mathrm{GH}(0.5 \%), 8) N . r+\mathrm{TW}(0.5 \%)+\mathrm{GLY}(2 \%)+\mathrm{SFO}(1 \%)+\mathrm{CMC}(0.5 \%), 9)$ $N . r+\mathrm{TW}(0.5 \%)+\mathrm{GLY}(2 \%)+\mathrm{HO}(1 \%)$ and 10$) N . r+\mathrm{TW}(0.5 \%)+\mathrm{GLY}(2 \%)+\mathrm{CMC}(0.5 \%)$ were emerged out as most promising and advanced stage formulations of $N$. rileyi.
\end{abstract}

How to view point the article : Patil, S.D. and Jadhav, R.S. (2016). Effect of various adjuvants on growth and development of the entomopathogenic fungi Nomuraea rileyi (Farlow) Samson. Internat. J. Plant Protec., 9(2) : 593-602, DOI : 10.15740/HAS/IJPP/9.2/593-602. 